\title{
CONFERENCIA MUNDIAL POR UN FUTURO PACIFICO Y SEGURO PARA TODOS LOS NIÑOS
}

En Diciembre de 1976, la Asamblea General de la ONU proclamó a 1979 como el Año Internacional del Niño, en conmemoración del XX aniversario de la Declaración de los Derechos del Niño. El Comité Preparatorio, reunido en Berlín en febrero de 1977 en su primera sesión, decidió que su gran iniciativa sería la Conferencia Mundial para el AIN. En la segunda sesión, celebrada en octubre de 1977, el Comité determinó el tema de la Conferencia: "Por un futuro pacífico y seguro para todos los niños", y la asistencia de representantes de organizaciones sociales, políticas y religiosas, especializadas en problemas de la infancia; representantes de los medios de información masiva; científicos; personalidades de la educación y la cultura; organizaciones sindicales, femeninas, juveniles, estudiantiles e infantiles; así como representantes de la ONU y de sus organismos especializados. Se acordó como mecánica, dentro de la conferencia, el trabajo por comisiones y sesiones plenarias. En septiembre del año de 1978, el Comité reunido en Ginebra, decidió como sede de la Conferencia Mundial la ciudad de Moscú, precisando los días del 7 al 11 de septiembre de 1979 como fecha de realización de tal evento.

Se reunieron en Moscú 700 delegados de 47 organizaciones internacionales y regionales, de 385 nacionalidades, y de más de 130 países del mundo. La conferencia estudió los siguientes aspectos:

1. Las condiciones económicas, sociales y legales necesarias para garantizar a todos los niños la vida, la salud y el bienestar. Protección para la madre y el niño (Comisión No.1).

2. La educación obligatoria enmarcada dentro de un espíritu de paz, amistad e independencia. La responsabilidad que tiene la sociedad en sus manifestaciones culturales, deportivas y recreativas para el complejo desarrollo de la personalidad del niño y del adolescente. El papel de los medios masivos de comunicación en la educación (Comisión No. 2).

3. La protección y solidaridad para todos los niños que viven en condiciones sociales y políticas difíciles, de violación de los Derechos Humanos: niños víctimas de la guerra, la agresión, explotación, opresión, fascismo, racismo y apartheid (Comisión No. 3).

4. La asistencia a los niños impedidos, a los huérfanos y a los abandonados (Comisión No. 4).

FREDA BROWN, Presidenta de la Conferencia presenté los siguientes datos:

"600 millones de niños del mundo viven en la miseria; 200 millones quedan con hambre cada día; donde hay guerra, los niños son los primeros en morir... Sólo uno de cada 20 niños que viven en los países en desarrollo goza de atención médica... 85 por ciento de los niños que viven en zonas rurales carecen de suficiente agua potable... 40 por ciento de niños inscritos en las escuelas se ven obligados a abandonarla.., tan sólo el 1 por ciento de los niños en edad preescolar tienen acceso a las instituciones preescolares... En Chile, Uruguay, Paraguay, Haití, Guatemala, El Salvador, la República Dominicana los niños son víctimas de regímenes dictatoriales antipopulares. En Chile hay 60.000 niños cuyos padres han sido asesinados, han desaparecido o están encarcelados... En Colombia trabajan tres millones de ni la Conferencia enfatizó en tres 
ideas, las cuales se deben tener en cuenta para que llegue a ser realidad en todos los países la Declaración de los Derechos del Niño, aprobada por las Naciones Unidas en 1959:

1. "La paz es la premisa vital-mente importante para resolver los problemas relacionados con la situación de los niños".

2. "La solución de los problemas de los niños depende de la solución de los problemas que se plantean ante la humanidad, y deben ser parte inalienable del desarrollo económico y social".

3. "El respeto y la efectividad de los derechos y las libertades fundamentales de la persona humana es condición sine qua non para el cumplimiento de la Declaración de los Derechos del Niño". "Donde se violan los Derechos Humanos se violan los Derechos del Niño".

Rosalía Montealegre 